\title{
Family Background, Educational Returns and Income Inequality
}

\author{
Zhilun Lin \\ Tianjin University of Finance and Economics, Tianjin, 300222, China
}

Keywords: return on education; selective bias; family background; propensity score matching

\begin{abstract}
In China, family background has an important impact on the returns on education, which in turn influences the degree of income inequality. This paper uses propensity score matching model to eliminate the influence of selective bias and estimate the educational return rate of children in different family backgrounds. It is found that the higher the education level of fathers, the lower the returns on education of children; the return rate of education for fathers who are party members and their children is higher; the returns on education for children of agricultural households is higher than that of non-agricultural households.
\end{abstract}

\section{Introduction}

Income inequality is a basic feature of our society today. With the development of the economy, income inequality gradually expands, leading to an ever-increasing gap between the rich and the poor in society and the formation of polarization. For the factors that affect income inequality, many scholars have studied from various aspects. Although a large number of literatures generally point out that policies, regions, industries, individuals, and other reasons may affect income inequality, the return on education also has an important impact on income.

Parents'educational level, whether they are party members or whether they have a non-agricultural residence account will affect the return rate of their children's education and thus affect the income level. However, for each microscopic individual, whether or not the university education is affected by endogenous factors, gender and age factors will influence the situation of the microscopic individual receiving university education. Such selective bias will make the estimation biased and cannot obtain the university education. The net effect of personal income makes it impossible to accurately compare the differences in educational returns in different family contexts. This paper uses the PSM model to eliminate the influence of selective bias and to measure and analyze the educational return rate under different family backgrounds.

Cheng Lei and He Hua (2012)[1] pointed out that with the continuous expansion of colleges and universities, the rate of return on education is decreasing year by year. In terms of the rate of return on education at different stages, the rate of return on education in primary and middle schools is decreasing, and that of high schools and technical schools is decreasing. The rate of return rose, and the rate of return on college education and masters declined, but the magnitude was not great. Huang Zhiling and Yao Xianguo (2009) pointed out that there is a serious gender discrimination in the labor market in China. Although the market wage payment structure is more biased towards men, the increase in the level of female education can effectively alleviate the degree of discrimination in the labor market. Therefore, there can be a higher return on education, which shows that education can ease the high degree of differentiation in the labor market in China. Du Duo and Peng Jing (2010)[2] showed that the return rate of education in municipalities was the highest, followed by provincial capital cities, and lowest in other cities. Zhong Yuning and Liu Hua (2007) pointed out that while the overall rate of return on education has risen, the gap in educational returns between different levels of education has also gradually widened.

However, there are few articles on whether there is a correlation between the rate of return on education and family background. Due to differences in factors such as economy, population, and regions, citizens' educational opportunities are seriously inequitable. There must be a clear relationship between the two. . Yao Xianguo, Huang Zhiling, and Su Zhenhua (2006) classified the family background and then used the Mincer equation to estimate the educational return rate under 
different family backgrounds. That is to say, the natural logarithm wage is used as the explanatory variable, and the education age is taken as the explanatory variable. , and use this coefficient of the explanatory variable in the regression as a measure of the return on education. However, this study ignores the influence of selective bias. A person's gender, age, and many other factors will affect his or her ability to go to college. Therefore, the regression coefficient of the explanatory variable is used as a measure of the return on education and contains confounding factors. The impact of this will cause some bias in the estimate. Therefore, the application of the PSM model eliminates this selective bias and conducts in-depth research on the effect of family background on educational returns and income distribution.

\section{Literature Review}

There are many studies on the rate of return on education at home and abroad. Cheng Lei and He Hua (2012) pointed out that with the continuous expansion of colleges and universities, the return rate of education is decreasing year by year. Specifically, the returns on education in 1997, 2000, 2004, 2006, and 2008 were 15.3. \%, 14.2\%, 13.3\%, 11.3\% and 10.2\%. In addition, in terms of the rate of return on education at different stages, the returns on education in elementary and junior high schools have decreased, the returns on high schools and technical schools have increased, and the returns on college education and masters have declined, but the rate is not very large. Huang Zhiling and Yao Xianguo (2009) pointed out that there is a serious gender discrimination in the labor market in China. Although the market wage payment structure is more biased towards men, the increase in the level of female education can effectively alleviate the degree of discrimination in the labor market. Therefore, there can be a higher return on education, which shows that education can ease the high degree of differentiation in the labor market in China. Du Duo and Peng Jing (2010) showed that the return rate of education in municipalities was the highest, followed by provincial capital cities, and lowest in other cities. Zhong Yuning and Liu Hua (2007) pointed out that while the overall rate of return on education has risen, the gap in educational returns between different levels of education has also gradually widened.

However, there are few articles on whether there is a correlation between the rate of return on education and family background. Due to differences in factors such as economy, population, and regions, citizens' educational opportunities are seriously inequitable. There must be a clear relationship between the two. . Yao Xianguo, Huang Zhiling, and Su Zhenhua (2006) classified the family background and then used the Mincer equation to estimate the educational return rate under different family backgrounds. That is to say, the natural logarithm wage is used as the explanatory variable, and the education age is taken as the explanatory variable. , and use this coefficient of the explanatory variable in the regression as a measure of the return on education. However, this study ignores the influence of selective bias. A person's gender, age, and many other factors will affect his or her ability to go to college. Therefore, the regression coefficient of the explanatory variable is used as a measure of the return on education and contains confounding factors. The impact of this will cause some bias in the estimate. Therefore, the application of the PSM model eliminates this selective bias and conducts in-depth research on the effect of family background on educational returns and income distribution.

\section{Model Assumptions}

The model used in this paper is a propensity score matching model. The first step:

$$
P_{i}=\alpha+\beta \text { age }_{i}+\gamma \operatorname{sex}_{i}+\eta D_{j i}+\varepsilon_{i}
$$

where $p_{i}$ is the indicator variable for whether to go to college, 0 means not in college, 1 means

that you have been in college; $\alpha$ for interception; $a g e_{i}$ for the individual's age, sex $x_{i}$ the individual's gender, 0 for women, 1 for men, $D_{j, i}$ Represents the remaining two family background variables. 
The second step: build a matching model for regression, get the value, that is, the return on education:

$$
\ln \text { wage }_{i}=\alpha+\beta p_{i}+\gamma P_{i}+\delta P_{i}\left(p_{i}-\mu_{p}\right)+\varepsilon_{i}
$$

$p_{i}$ is the predicted value in the first step, which is the sample mean of the predicted value.

\section{Empirical Studies}

\subsection{Data Sources.}

This article uses 2016 CFPS microdata. Because the research is on the influence of family background on the differentiation of education returns, the variables selected are the account, age, gender, and personal after-tax net income of the respondent, and the education level and political profile of the interviewee's father. The selection is as follows:

sex. There is a certain degree of "peace of boys" phenomenon in the society, women's employment pressure is greater than men's, but if the education level of women is improved, it will help reduce the degree of discrimination in the labor market.Age. The age of an individual represents the age in which it is located. There are different probabilities for college education in different years.

Father's educational level ( $\left.D_{1}\right), 0$ means father's college degree or below, 1 means father's college degree or above. The father's political appearance $\left(D_{2}\right), 0$ means that the father is not a member of the Communist Party of China, and 1 means that the father is a member of the Chinese Communist Party. Account of the child $\left(D_{3}\right), 0$ means the child is an agricultural account, and 1 means the child is a non-agricultural account.

\subsection{Propensity Scoring Process and Matching Process.}

The individual's gender, age, father's political outlook, and father's education level were taken as the explanatory variables of the selection equation, and the propensity value was scored. After iterating and deleting variables that do not meet the equilibrium conditions, binary logit regression results are obtained. To get an estimate of the return on education, we next match the data. There are four common data matching methods: Nearest-Neighbor Matching, Stratification Matching, Radius Matching, and Kernel Matching. The following four methods are used for matching analysis. The results are shown in Table 1 below:

Table 1 Dual logit regression results for children receiving college education

\begin{tabular}{|c|c|c|c|c|c|c|}
\hline Edu & D1(1) & D1(0) & D2(1) & D2(0) & D3(1) & D3(0) \\
\hline Sex & $\begin{array}{c}-0.0176903 \\
{[0.959]}\end{array}$ & $\begin{array}{c}0.0094885 \\
{[0.822]}\end{array}$ & $\begin{array}{c}-0.0538657 \\
{[0.545]}\end{array}$ & $\begin{array}{c}0.0512477 \\
{[0.315]}\end{array}$ & $\begin{array}{c}0.0501676 \\
{[0.292]}\end{array}$ & $\begin{array}{c}-0.113928 \\
{[0.179]}\end{array}$ \\
\hline Age & $\begin{array}{c}-0.0584069^{* * *} \\
{[0.002]}\end{array}$ & & $\begin{array}{c}-.053195^{* * *} \\
{[0.000]}\end{array}$ & $\begin{array}{c}-.0399988^{* * *} \\
{[0.000]}\end{array}$ & & \\
\hline D1 & & & $\begin{array}{c}0.2943845 \\
{[0.101]}\end{array}$ & $\begin{array}{c}1.4695737^{* *} \\
{[0.025]}\end{array}$ & $\begin{array}{c}0.3759112^{* * *} \\
{[0.005]}\end{array}$ & \\
\hline D2 & $\begin{array}{c}0.0301107 \\
{[0.962]}\end{array}$ & & & & $\begin{array}{c}0.1234869^{* *} \\
{[0.021]}\end{array}$ & $\begin{array}{c}0.1582945 \\
{[0.168]}\end{array}$ \\
\hline D3 & & $\begin{array}{c}1.207991^{* * *} \\
{[0.000]}\end{array}$ & $\begin{array}{c}1.427834^{* * *} \\
{[0.000]}\end{array}$ & $\begin{array}{c}1.470222^{* * *} \\
{[0.000]}\end{array}$ & & \\
\hline _Cons & $\begin{array}{c}1.235616^{* *} \\
{[0.048]}\end{array}$ & $\begin{array}{c}-2.305941^{* * *} \\
{[0.000]}\end{array}$ & $\begin{array}{c}-0.2788338 \\
{[0.151]}\end{array}$ & $\begin{array}{c}-1.093186^{* * *} \\
{[0.000]}\end{array}$ & $\begin{array}{c}-1.151839^{* * *} \\
{[0.000]}\end{array}$ & $\begin{array}{c}-2.254647^{* * *} \\
{[0.000]}\end{array}$ \\
\hline
\end{tabular}


Through the late analysis,First of all,Before the analysis is conducted, many people think that the higher the degree of education of the father, the more accurate career planning and employment advice the child can give, so that the child can find a better job for them, that is, a generation. The higher the degree of education, the more positive it will be for the next generation. However, after analysis, if his father has a college degree or less, his child's educational return rate is about $25 \%$, and his father's bachelor's degree or above, his child's educational return rate is about $17 \%$, but it's a lot lower than the former. The conjecture is inconsistent. The probable reason is that the father has a high level of education, the family's economic status is generally better, the children are in the status quo, the desire to make money is not strong, the work is not hard, so the return on education is low; while the father's education is low, the family's Economic conditions are generally poor, and children's desire to change the status quo is even stronger and they will work harder, so the return on education will be higher than the former. In this way, university education can help reduce the income gap of the offspring, thus alleviating the status of income inequality in the entire society.

Second, he father's non-Communist Party members' return on education for their children is about 22\%, their father is a member of the Communist Party of China, and their child's educational return rate is about $25 \%$, which is $13.64 \%$ higher than the former. This shows that the father's political outlook It has a positive effect on the return on education of children. The reason for this result may be due to: First, the nepotism of the labor market. China is a country with a very strong family relationship. Parents will provide the greatest support for their children in finding a job. The father is a party member and means that he has more contacts, experience and social resources and can help his children find a better job. Ideal job. The identity of the father's party members is even more powerful for the children's job search. Second, it may also be that the father's own ability is strong, and therefore the child's innate ability is also a result of the strong cause. If the father is a member of the party and the father is not a member of the party's children if they get the same work, the former's children are more capable and will get better jobs and higher income at work. In summary, the father's political outlook will widen the social income gap.

At last,Many people think that children from rural households are poor and do not have a good social background. A good academic qualification does not mean that they can find a good job. They also want to stay in the city and their living expenses are a great burden. In addition, many employers require applicants to have non-agricultural accounts when hiring. This barrier will stop those who are able to do so, so that they cannot get a good job. Therefore, the generational cycle has become a vicious circle. change destiny. However, from the results of the analysis, this is not the case. The returns on education of children in rural households are higher, which shows that the difference in wage income between rural children receiving college education and not receiving university education is huge. Therefore, it is particularly necessary to improve the educational environment in poor rural areas. This will help increase the income level of rural residents and narrow the widening income gap between urban and rural areas.

No matter what kind of family background, receiving university education will have a positive effect on wage income to a certain extent, and the promotion effect is above $15 \%$. This shows that education is the most important task now and in the future. The popularization of university education is not only It can increase the overall income level, and it can also stimulate macroeconomic growth, narrow the income gap, and alleviate polarization between the rich and the poor.

\section{Conclusion}

According to the analysis, we can draw the following conclusions: First, education has the effect of narrowing the income gap of the offspring. Second, the reason why the father's identity is the higher return rate for the party members' children's education, although it may be caused by their own innate ability, However, whether or not non-market operations from political identities are worthy of the attention of the decision-making departments. Third, it is particularly necessary to improve the education environment in poor rural areas, which is conducive to raising the income level of rural residents and narrowing the widening income gap between urban and rural areas. 


\section{References}

[1] L.Chen, H.He. Analysis of the Influence of Enlarging Enrollment in Higher Education on the Return of Urban Education: An Empirical Study Based on CHNS Data [J]. China Regional Economy, 2012, (3).(in chinese)

[2] D.Du, J.Peng. Research on urban difference in educational return rate[J]. China Population Science, 2010, (5).(in chinese)

[3] T.Wu. Research on the rights of rural women in rural areas in China [D]. Central University for Nationalities, 2007.

[4] Y.P.Liu. Educational Sociology Analysis of Employment Discrimination Among Female Higher Educators [J]. Journal of Sichuan Administration College, 2013, (2).

[5] X.X.Zhang. Research on the Return of Urban and Rural Education in China: Empirical Analysis Based on CHIP2002 Data [J]. Journal of Xiamen University(Philosophy and Social Sciences), 2012,(6).(in Chinese)

[6] Meghir C, Palme M. Educational reform, ability, and family background [J]. The American Economic Review, 2005, (1): 414-424.

[7] JACOB.M. Schooling, Experience, and Earnings [M]. New York: NationaI Bureau of Economic Research, 1974.

[8] MARGARET.M.F, NGAN.D. Differential Remits to, and Contributions of, Education in Urban China’s Seg-mented Labor Markets [J]. Pacific Economic Review, 2004, 9(3): 173-189.

[9] ALAND.B, SCOTT.R. Reconciling the Returns to Education in Off-Farm Wage Employment in Rural China [J]. Review of Development Economics, 2008, 12(1):57-71. 